\title{
Allergic contact dermatitis due to urethane acrylate in ultraviolet cured inks
}

\author{
J R NETHERCOTT, H R JAKUBOVIC, C PILGER, AND J W SMITH \\ From the Department of Occupational and Environmental Health, St Michael's Hospital, University of \\ Toronto, Toronto, Ontario, Canada
}

\begin{abstract}
Seven workers exposed to ultraviolet printing inks developed contact dermatitis. Six cases were allergic and one irritant. A urethane acrylate resin accounted for five cases of sensitisation, one of which was also sensitive to pentaerythritol triacrylate and another also to an epoxy acrylate resin. One instance of allergy to trimethylpropane triacrylate accounted for the sixth case of contact dermatitis in this group of workers. An irritant reaction is presumed to account for the dermatitis in the individual not proved to have cutaneous allergy by patch tests. In this instance trimethylpropane triacrylate was thought to be the most likely irritating agent. Laboratory investigation proved urethane acrylate to be an allergen. The results of investigations of the sensitisation potentials of urethane acrylate, methylmethacrylate, epoxy acrylate resins, toluene-2,4diisocyanate, and other multifunctional acrylic monomers in the albino guinea pig are presented. The interpretation of such predictive tests is discussed.
\end{abstract}

Inks and coatings based on acrylated resins, reactive low molecular weight acrylates, and light absorbing chemicals have established specific uses in industry in the last decade. ${ }^{1}$ These materials have not become as widely used as was originally expected ${ }^{2}$ due to the cost of raw materials and health problems, principally cutaneous disease, that have arisen in workers manufacturing them ${ }^{3-5}$ and using the finished products containing them. ${ }^{6-8}$

Binding of acrylated oligomer such as acrylated alkyds, acrylated epoxy resins (EAs), polyester acrylates, or acrylated vegetable oils such as acrylated linseed oil) (fig 1) to dry the ink is accomplished by a highly reactive acrylate with more than one acrylate functional group, known as a multifunctional acrylic monomer (MFAs), which acts as a cross linking agent chemically reacting with two or more adjacent oligomers to bind them together. These MFAs, which are more highly reactive than the more well known monomeric acrylic monomers_for instance, methyl methacrylate (MMA)-include: pentaerythritol triacrylate (PETA), trimethyl propane triacrylate (TMPTA), and hexanediol diacrylate (HDODA) (fig 2). Low molecular weight EAs and urethane acrylate resins (UA) are now being used as cross linking agents replacing MFAs (fig 3). A

Received 6 January 1982

Accepted 26 August 1982 chromophore such as an aromatic ketone, benzoin, or a chlorinated aromatic compound which absorbs photons of ultraviolet light (emitted from a fluorescent tube with a continuous emission of light of $300-400 \mathrm{~nm}$ wave length), transfers the energy absorbed to the cross linking acrylic chemical by homolytic fragmentation of the photoinitiator or excitation of the photoinitiator to a triplet state with electron transfer to the cross linking chemical. The activated acrylate thus formed then binds to the acrylated ends of the polymer effecting cure, ${ }^{2}$ which results in virtually instantaneous drying of the ink or coating. As the low molecular weight acrylate is of low viscosity, it may often be used as a diluent for the other system components rather than a hydrocarbon solvent, as has been the case in conventional inks and coatings. This offers the advantage that almost no loss of coating thickness occurs with drying as the diluent is bound up in the final cured or dried material rather than evaporating as in conventional systems. This feature has great usefulness in certain applications-for instance, in coating systems to prevent dental caries where the dental coating applied in this fashion dries without leaving any breaks that might allow passage of bacteria into the coated tooth. ${ }^{3}$

Allergic contact dermatitis due to the acrylate cross linkers PETA, TMPTA, and HDODA have been reported. ${ }^{145}$ Sensitisation to EA resin has also been documented..$^{4-9}$ EAs and PETA have been 
<smiles>C=CC(=O)OCCCOC(=O)CCCCCC(=O)OCC</smiles>

Acrylated alkyd<smiles>C=CC(=O)OCC(CC)(COC(=O)C=C)COC(=O)CCC(=O)OCC(CC)(COC(=O)C=C)COC(=O)C=C</smiles>

Acrylated epoxy<smiles>C=CC(=O)OCC(O)COc1cccc(C(C)(C)c2cccc(OCC(O)COC(=O)C=C)c2)c1</smiles><smiles>C=CC(=O)OCC(COC(=O)C=C)(COC(=O)C=C)COC(=O)C=C</smiles>

Trimethylolopropane triacrylate (TMPTA)<smiles>C=CC(=O)OCC(CC)(COC(=O)C=C)COC(=O)C=C</smiles>

Hexanediol diacrylate (HDODA)<smiles>C=CC(=O)OCCCCCCCOC(=O)C=C</smiles>

Fig 2 Some multifunctional acrylic chemicals in use as cross linking agents in ultraviolet curing systems.
Fig 1 Acrylated oligomers commonly in use commercially. shown to possess cutaneous sensitisation potential in the guinea pig. ${ }^{70}$

Our purpose is to report a group of workers handling ultraviolet sensitive printing inks who developed cutaneous allergy to UA in the inks and to present experimental evidence regarding the relative allergenic potential of urethane acrylate compared with other sensitisers using a guinea pig model.

\section{Printing process}

All affected workers were employed in a plant that manufactured plastic food containers. The containers had print applied to their exterior by way of an offset printing process. The plastic containers were fed to the printing plates on an apparatus resembling a "ferris wheel" (fig 4). The container was rotated against the printing plates as it went around and was then discharged on to a conveyor belt that took the printed container past a bank of intense ultraviolet lamps to dry the printed surface (fig 5 ). The workers were principally exposed to the inks when they refilled reservoirs (fig 6) and when using solvents to clean up the press between press runs. Gloves were not routinely worn during either of these procedures. Occasionally workers had to mix inks to produce a particular colour, and under certain condi- 


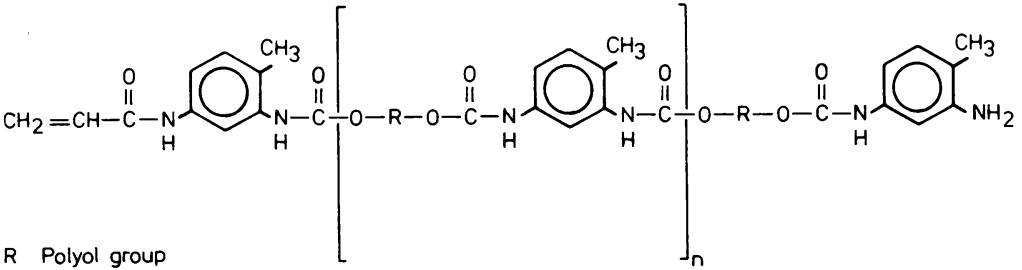

Fig 3 Structure of urethane acrylate resins.

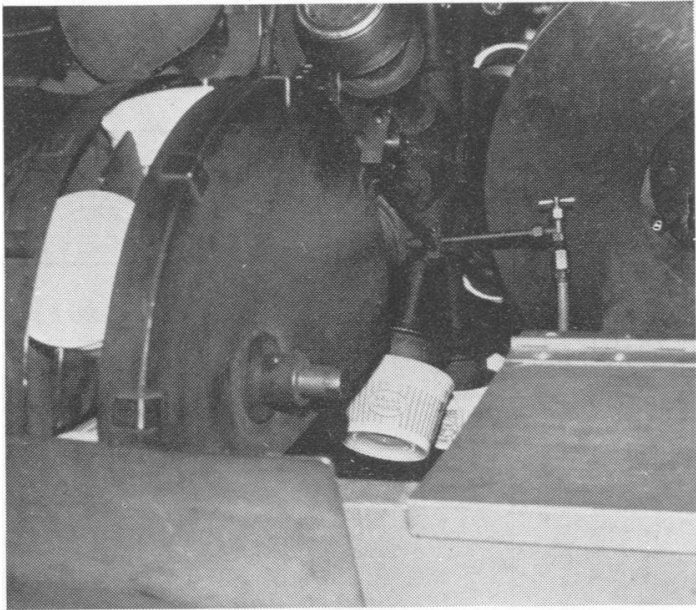

Fig 4 Interstices of offset press used to print on containers. Containers move on arms of wheel to engage printing plates, then spin around on end of arm through a $360^{\circ}$ arch to allow application of print to entire outside surface of container.

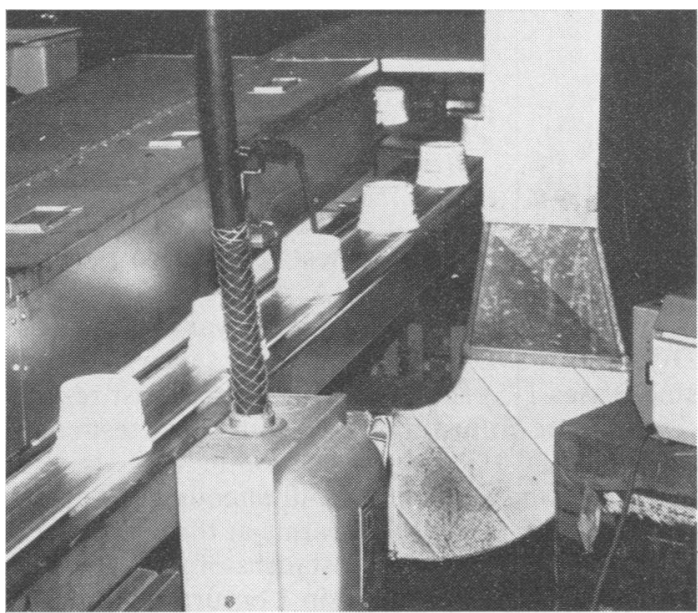

Fig 5 Conveyor belt carrying freshly printed containers into tunnel lined with intense ultraviolet light emitting fuorescent tubes to dry ink. Note exhaust to remove ozone and nitrous oxide.

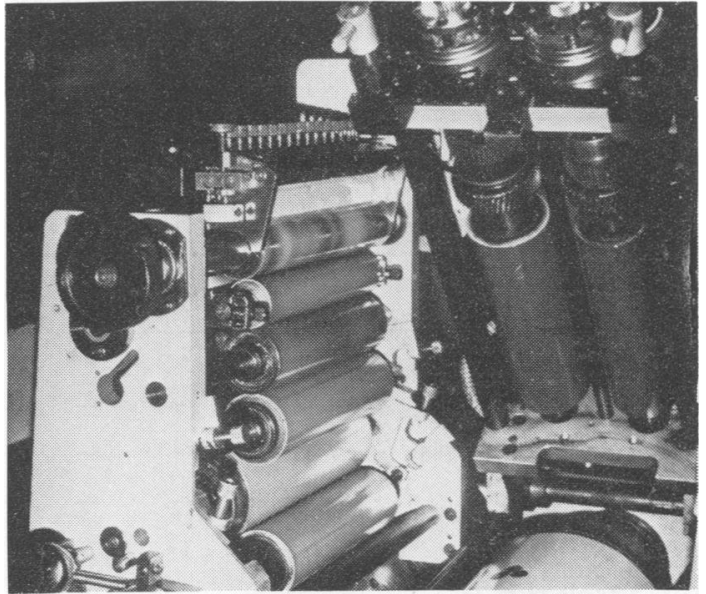

Fig 6 Reservoirs for ink that have to be filled by hand.

tions it was also necessary to add TMPTA to a given ink to reduce the ink viscosity to facilitate better dispersion of the ink on the printed surface or to enhance the cure rate to allow adequate drying. During both the formulation of the specific ink colours and the dilution of inks with TMPTA there was a serious risk of skin contamination with the ultraviolet curing system components.

\section{CLINICAL FEATURES}

Eight press operators and two foremen worked in this plant; seven experienced cutaneous problems varying from severe eczematous dermatitis of the dorsal hands, forearms, arms, neck, and eyelids (case 1) to erythematous scaling in distinct evanescent patches on the dorsal hands (case 7) (table 1).

\section{CLINICAL INVESTIGATION}

\section{Materials and methods}

The chemicals outlined in table 2 were used for patch tests. All chemicals used had been shown to be non-irritant in the concentration and vehicle tested in 20 normal human subjects. The materials were applied to "A1-test strips" (Hollister-Stier Ltd) that were then fixed to the upper back of each subject 
Table 1 Findings in workers with cutaneous complaints

\begin{tabular}{|c|c|c|c|c|}
\hline Case & Sex & Job description & Symptoms and signs & Clinical diagnosis \\
\hline 1 & $\mathbf{F}$ & Machine operator & $\begin{array}{l}\text { Itchy red patches on face, neck, forearms, } \\
\text { and hands when working with inks }\end{array}$ & Allergic contact dermatitis \\
\hline 2 & $\mathbf{M}$ & Foreman in printing department & $\begin{array}{l}\text { Itchy red patches on face, ears, wrists } \\
\text { when working with inks }\end{array}$ & Allergic contact dermatitis \\
\hline 3 & $\mathbf{M}$ & Foreman in printing department & $\begin{array}{l}\text { Itchy red patches on periorbital skin and } \\
\text { forearms when working with inks }\end{array}$ & Allergic contact dermatitis \\
\hline 4 & $\mathbf{F}$ & Mixing inks, machine operator & $\begin{array}{l}\text { Itchy red patches on neck, forearms, } \\
\text { hands when working with inks }\end{array}$ & Allergic contact dermatitis \\
\hline 5 & $\mathbf{F}$ & Machine operator & $\begin{array}{l}\text { Itchy red patches on periorbital skin, } \\
\text { forearms, hands, when working with inks }\end{array}$ & Allergic contact dermatitis \\
\hline 6 & $\mathbf{F}$ & Machine operator & $\begin{array}{l}\text { Itchy, burning red swollen patches under } \\
\text { eyes when working with inks }\end{array}$ & Allergic contact dermatitis \\
\hline 7 & $\mathbf{F}$ & Machine operator & $\begin{array}{l}\text { Erythematous, slightly pruritic patch on } \\
\text { arms }\end{array}$ & Irritant contact dermatitis \\
\hline
\end{tabular}

Table 2 Results of epicutaneous tests in seven workers patch tested

\begin{tabular}{|c|c|c|c|c|c|c|c|c|c|c|c|c|}
\hline Chemicals & $\begin{array}{l}\text { Case } 1 \\
48 h\end{array}$ & $96 h$ & $\begin{array}{l}\text { Case } 2 \\
48 h\end{array}$ & $96 h$ & $\begin{array}{l}\text { Case } 3 \\
48 \mathrm{~h}\end{array}$ & $96 h$ & $\begin{array}{l}\text { Case } 4 \\
48 \mathrm{~h}\end{array}$ & $96 h$ & $\begin{array}{l}\text { Case } 5 \\
48 \mathrm{~h}\end{array}$ & $96 h$ & $\begin{array}{l}\text { Case } 6 \\
48 h\end{array}$ & $96 h$ \\
\hline $\begin{array}{l}\text { Urethane acrylate } 0.1 \% \text { in } \\
\text { petrolatum }\end{array}$ & $3+$ & $3+$ & $2+$ & $2+$ & $2+$ & $2+$ & $2+$ & $2+$ & $2+$ & $2+$ & - & - \\
\hline $\begin{array}{c}\text { Pentaerythritol triacrylate } \\
0.1 \% \text { in petrolatum }\end{array}$ & $3+$ & $3+$ & - & - & - & - & - & - & - & - & - & - \\
\hline $\begin{array}{c}\text { Trimethylpropane triacrylate } \\
0.1 \% \text { in petrolatum }\end{array}$ & - & - & - & - & - & - & - & - & - & - & $2+$ & $2+$ \\
\hline $\begin{array}{l}\text { Hexanediol diacrylate } \\
0.1 \% \text { in petrolatum }\end{array}$ & - & - & - & - & - & - & - & - & - & - & - & - \\
\hline $\begin{array}{c}\text { Epoxy acrylate resin } 1 \\
1 \% \text { in petrolatum }\end{array}$ & - & - & $1+$ & $1+$ & - & - & - & - & - & - & - & - \\
\hline $\begin{array}{c}\text { Epoxy acrylate resin } 2 \\
1 \% \text { in petrolatum }\end{array}$ & - & - & - & - & - & - & - & - & - & - & - & - \\
\hline $\begin{array}{c}\text { Epoxy acrylate resin } 3 \\
1 \% \text { in petrolatum }\end{array}$ & - & - & - & - & - & - & - & - & - & - & - & - \\
\hline $\begin{array}{c}\text { Epoxy acrylate resin } 4 \\
1 \% \text { in petrolatum }\end{array}$ & - & - & - & - & - & - & - & - & - & - & - & - \\
\hline $\begin{array}{l}\text { Toluene } 2,4 \text { disocyanate } \\
0.1 \% \text { in acetone }\end{array}$ & - & - & - & - & - & - & - & - & - & - & - & - \\
\hline
\end{tabular}

$0=$ No reaction.

$1+=$ Macular erythema.

$2+=$ Oedematous or vesicular reaction.

$3+=$ Spreading, bullous, or ulcerative reaction.

with Dermicel tape (Johnson \& Johnson Ltd) as recommended by the North American Contact Dermatitis Group."

Patches were removed at $\mathbf{4 8}$ hours. The sites were examined and scored after the pressure effect of the "A1-test strip" had resolved-that is, after about 30 minutes. The scoring system recommended by International Contact Dermatitis Group ${ }^{12}$ was used as noted in table 2 . The sites were examined further at 72 and 96 hours.

In case 1 a $2 \mathrm{~mm}$ punch biopsy of the skin was taken from the centre of the urethane acrylate patch test site shortly after the $\mathbf{4 8}$ hour visual scoring procedure. The skin biopsy specimen was fixed in formalin and processed for light microscopic examination using haematoxylin-phloxine-saffron staining.

\section{RESULTS}

Table 2 outlines the patch test results. No positive reactions were elicited to EA resin 2, EA resin 3, EA resin 4, toluene-2,4-diisocyanate (TDI), HDODA, or MMA. Five of the seven workers tested (cases 1-5) showed positive patch test results to UA. Figure 7 illustrates a $\mathbf{4 8}$ hour patch test reaction to UA $0.1 \%$ in petrolatum in case 1 ; this patient also manifested a simultaneous autosensitisation dermatitis of her forearms at the time of the positive patch test. Single instances of sensitivity to PETA, TMPTA, and EA resin 1 occurred. TMPTA was the sole sensitiser in one case (case 6) while in the case of PETA and EA resin 1 the positive epicutaneous tests were in association with a positive response to urethane acrylate. 


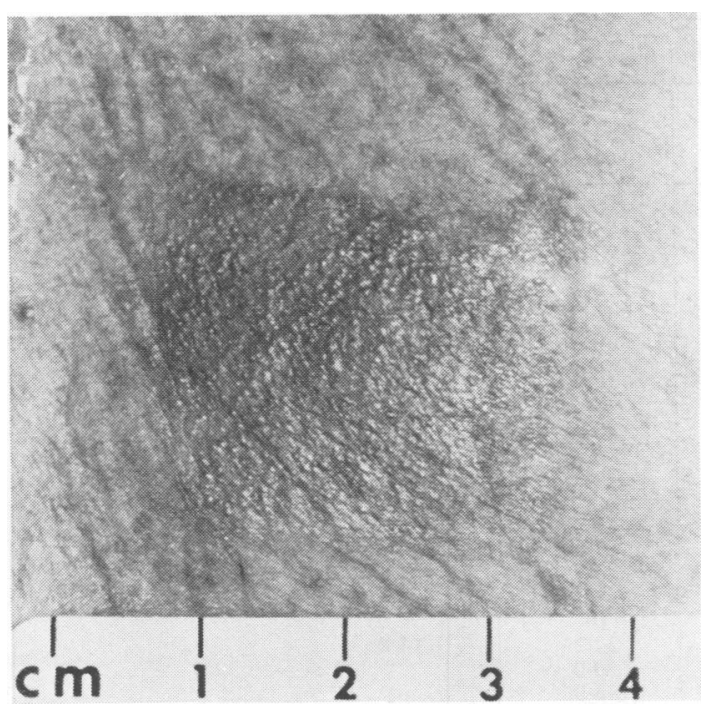

Fig 7 Site of cutaneous reaction to a patch test with urethane acrylate $0.1 \%$ in petrolatum at 48 hours in case 1.

The skin biopsy specimen in case 1 taken from the UA patch test reaction site at 48 hours showed epidermal spongiosis, dermal oedema, and a superficial perivascular lymphocytic infiltrate with exocytosis (fig 8) consistent with allergic contact dermatitis. ${ }^{13}$

\section{LABORATORY INVESTIGATION}

\section{Sensitisation potential}

Animals-Albino Hartley/Dalkin strain female guinea pigs weighing 300-500 g were obtained from the Connaught Laboratories, Toronto, Canada. They were housed in metal cages and fed Purina Guinea-Pig Chow and fresh water freely.

\section{Irritancy testing}

Various strengths of UA, TMPTA, HDODA, PETA, MMA, and tripropylene glycol diacrylate (TPGDA) in propylene glycol, all of which were fully dissolved or fully agitated if not entirely miscible, were intradermally injected into groups of 10 control guinea pigs. The animals were examined 24 hours after injection to determine the maximum concentration that did not cause severe injury or systemic toxicity. This concentration was used as the highest concentration in the subsequent sensitisation induction procedure.

Other groups of 10 control guinea pigs were topically exposed to the seven chemicals at various concentrations in petrolatum. Three concentrations of each chemical were applied to "A1-test strips" that were affixed to the animals' shaved flanks by occlusive tape (Blenderm, 3M Company) that was then covered by a three inch $(7.6 \mathrm{~cm})$ elastic adhesive bandage (Elastoplast, Smith and Nephew Co) wrapped firmly around their torsos. The bandages were removed after 24 hours and the sites were examined at 48 hours for evidence of reaction. The nonirritant concentration ascertained by this method was used to patch test the animals after the sensitisation procedure to determine whether they had become hypersensitive.

\section{Sensitisation procedure}

The method described by Magnusson and Kligman ${ }^{14}$ was used but with multiple intradermal induction

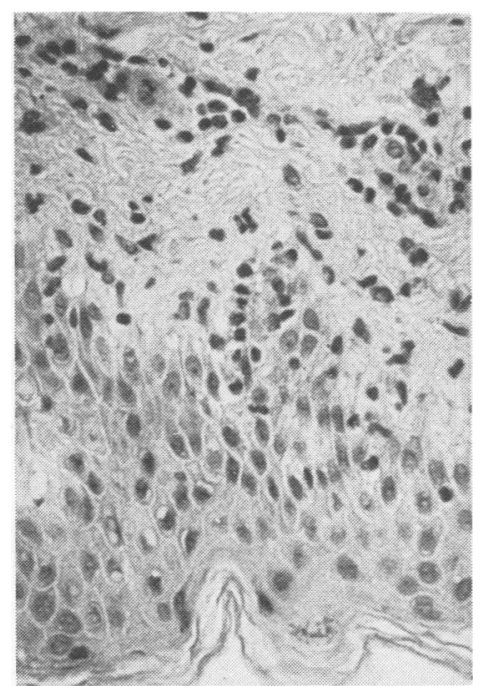

Fig 8 Biopsy specimen of the positive patch test in case 1 at 48 hours. Note epidermal spongiosis and lymphocytic perivascular infiltrate.

Haematoxylin-phloxine-saffron strain $(400 \times)$. 
Table 3 Percentage of animals sensitised, comparative sensitisation values, and various induction and challenge parameters for acrylic monomers, toluene diisocyanate, and urethane acrylate

\begin{tabular}{|c|c|c|c|c|c|}
\hline Chemical & $\begin{array}{l}\text { Intradermal } \\
\text { induction } \\
\text { concentration }\end{array}$ & $\begin{array}{l}\text { No of } \\
\text { animals }\end{array}$ & $\begin{array}{l}\text { No } \\
\text { sensitised }\end{array}$ & $\begin{array}{l}\% \text { Sensitised } \\
\text { by probit } \\
\text { calculations }\end{array}$ & $\begin{array}{l}\text { Intradermal sensitising } \\
\text { concentration for } 50 \% \text { of the } \\
\text { animals }\left(I D S C_{50}\right) \text { in \% }\end{array}$ \\
\hline TDI & $2 \cdot 5$ & 10 & 5 & $\mathrm{NC}$ & $2 \cdot 5$ \\
\hline TMPTA & $\begin{array}{r}0.5 \\
10.0\end{array}$ & $\begin{array}{l}10 \\
20\end{array}$ & $\begin{array}{r}4 \\
10\end{array}$ & $\begin{array}{l}20 \\
58 \cdot 3\end{array}$ & $5 \cdot 4$ \\
\hline HDODA & $\begin{array}{l}0 \cdot 83 \\
2 \cdot 5 \\
5 \cdot 0 \\
7 \cdot 5\end{array}$ & $\begin{array}{l}10 \\
10 \\
10 \\
10\end{array}$ & $\begin{array}{l}1 \\
3 \\
5 \\
6\end{array}$ & $\begin{array}{l}3.9 \\
20 \\
50 \\
79 \cdot 0\end{array}$ & $4 \cdot 3$ \\
\hline TPGDA & $\begin{array}{l}1 \cdot 0 \\
2 \cdot 5 \\
5 \cdot 0 \\
8 \cdot 5\end{array}$ & $\begin{array}{r}10 \\
10 \\
10 \\
6\end{array}$ & $\begin{array}{l}3 \\
4 \\
5 \\
3\end{array}$ & $\begin{array}{l}12 \cdot 5 \\
33 \cdot 3 \\
60 \cdot 0 \\
83 \cdot 3\end{array}$ & $3 \cdot 5$ \\
\hline MMA & $\begin{array}{r}5 \\
10 \\
15 \\
25\end{array}$ & $\begin{array}{l}5 \\
5 \\
5 \\
5\end{array}$ & $\begin{array}{l}0 \\
2 \\
2 \\
4\end{array}$ & $\begin{array}{c}0 \\
22 \cdot 2 \\
50 \cdot 0 \\
88 \cdot 9\end{array}$ & $14 \cdot 8$ \\
\hline UA & $\begin{array}{l}7 \cdot 5 \\
15 \cdot 0 \\
39\end{array}$ & $\begin{array}{l}10 \\
10 \\
10\end{array}$ & $\begin{array}{r}7 \\
9 \\
10\end{array}$ & $\begin{array}{l}63 \cdot 6 \\
94 \cdot 1 \\
100\end{array}$ & $5 \cdot 7^{*}$ \\
\hline
\end{tabular}

* Extrapolated value.

$\mathrm{NC}=$ No probit calculation performed.

PETA = Pentaerythritol triacrylate.

TDI = Toluene-2,4-diisocyanate.

HDODA $=$ Hexanediol diacrylate.

TPGDA = Tripropylene glycol diacrylate.

TMPTA = Trimethyl propane triacrylate.

MMA = Methyl methacrylate.

$\mathrm{UA}=$ Urethane acrylate.

concentrations administered. Table 3 notes the number of animals used at each intradermal concentration. Induction was performed in two stages. In the first stage either side of the shoulder region was injected intradermally. Three pairs of intradermal injections of the following composition were made into each group of animals:

(1) $0.1 \mathrm{ml}$ of the respective chemical in propylene glycol in the concentration noted in table 3 .

(2) $0.05 \mathrm{ml}$ of Freund's adjuvant (Freund's complete adjuvant, Difco Laboratories, Detroit, Michigan) mixed with $0.05 \mathrm{ml}$ of the chemical in propylene glycol injected as in (1).

(3) $0.1 \mathrm{ml}$ of Freund's complete adjuvant.

One week after injection the shoulder region of each animal was clipped. The six chemicals were applied in their respective concentrations in petrolatum, as noted in table 3 , on a $2 \mathrm{~cm} \times 4 \mathrm{~cm} 3 \mathrm{MM}$ Whatman filter paper that was applied over the sites of previous intradermal injection. The filter paper was held in place by impervious plastic tape (Blenderm, 3M Company) covered with a three-inch $(7.6 \mathrm{~cm})$ elastic adhesive bandage wrapped firmly about the animals. The bandages were removed 48 hours after they were applied.

\section{Challenge testing}

All animals were challenged two weeks after topical exposure. A $5 \mathrm{~cm} \times 5 \mathrm{~cm}$ area of the flank was clipped and then shaved with care to avoid abrading the skin. The challenge concentrations were nonirritant concentrations that had been determined in control animals as described above. The patches were applied as described above to assess irritancy. After 24 hours the patches were removed. The sites were examined at 48 hours for evidence of reaction; no endeavour was made to score the intensity of the reaction.

\section{RESULTS}

Table 3 notes the proportion of animals exhibiting reactions. Probit analysis was carried out using logprobability paper to calculate the intradermal (ID) concentration required to sensitise half the guineapigs $\left(\right.$ IDSC $_{50}$ ), except for TDI, which was tested at only one concentration..$^{15}$ The sensitisation potential of each of the chemicals was compared with that of PETA and MMA as noted in table 3.

\section{IRRITANCY POTENTIAL}

Animals

Six New Zealand white female adult rabbits weighing about $500 \mathrm{~g}$, obtained from the Guelph Rabbitry, Guelph, Ontario, were housed individually in metal cages and fed Purina Rabbit Chow and fresh water freely. 


\section{Method}

The method described by Draize and associates ${ }^{16}$ was used. After shaving the lower back of the rabbits, $0.5 \mathrm{ml}$ of $100 \%$ urethane acrylate was applied to the skin to an abraded and non-abraded site of $2 \mathrm{~cm} \times 2 \mathrm{~cm}$. The two sites were occluded with sterile $2 \mathrm{~cm} \times 2 \mathrm{~cm}$ gauze squares that were in turn held in place with an elastic adhesive bandage. The occlusive bandages and gauze were removed after 24 hours, and the sites were examined at 48 hours after application for evidence of cutaneous reaction. Reactions were scored using the standard method. ${ }^{16}$

\section{Results}

The cutaneous irritancy score determined by this experiment was $0 \cdot 75 / 8$.

\section{INFRARED AND HIGH PRESSURE LIQUID CHROMATOGRAPHY INVESTIGATION OF URETHANE ACRYLATE}

Technical grade urethane acrylate supplied to us by the manufacturer of the printing ink was analysed by infrared spectroscopy. No absorbance was detected in the $2260 \mathrm{~cm}^{-1}$ region where the isocyanate group absorbance should be found. A sample was mixed with toluene-2,4-diisocyante to give a concentration of $0.606 \% \mathrm{TDI} \mathrm{w} / \mathrm{w}$. This "doped" sample yielded a readily detectable absorbance at $2260 \mathrm{~cm}^{-1}$ due to the added diisocyanate. It was accordingly concluded that the urethane acrylate as supplied contained less than $0.6 \%$ free isocyanate. Samples of UA, PETA, TMPTA, and HDODA were analysed by a reverse phase high pressure liquid chromatograph equipped with a $254 \mathrm{~nm}$ fixed wavelength detector and a $30 \mathrm{~cm}$ octadecylsilane column. The instrument was operated in programmed gradient elution mode with a water/acetonitrile solvent system. Flow rate was $0.8 \mathrm{ml} /$ minute with a gradient running from $30 \%$ acetonitrile to $100 \%$ in 10 minutes. Total analysis time was 14 minutes.

The urethane acrylate chromatogram consisted of two major peaks that could not be completely resolved and four minor peaks, which together represented $9 \%$ of the total peak area.

Chromatography of TMPTA and HDODA under the same instrument conditions yielded a single peak for each. Retention times did not match the retention times of any of the components in the urethane acrylate sample.

The PETA sample, when chromatographed under the same conditions, yielded six peaks, none of which had retention times matching those of the urethane acrylate components. The five minor peaks in the PETA chromatogram were assumed to represent hydrolysis products of PETA, present as impurities. One of these was identified as acrylic acid by comparison with a chromatogram of an authentic sample of the acid. The other components were not investigated further. No peak was detected in the urethane acrylate chromatogram with the same retention time as acrylic acid.

Based on the HPLC data, it was concluded that the urethane acrylate as supplied contained no PETA, TMPTA, HDODA, or free acrylic acid.

\section{Comment}

The cutaneous disease of the seven affected workers was characteristic of contact dermatitis, based on the distribution and character of the lesions and the time course of the eruptions, all of which support the diagnosis. Historical data elicited from the workers confirmed a relation to work.

It is well recognised that the light sensitive inks to which these workers were exposed possess components with both irritant and allergic properties. ${ }^{13-8}$ Initial investigation in case 1 suggested that PETA was the culprit, but when it was discovered that it was not in the ink formulations in use at that time in the plant further investigation was undertaken. This led to the discovery of positive epicutaneous tests to urethane acrylate in case 1 and five other workers. Individuals sensitive to TMPTA and EA 1 resin in addition to urethane acrylate were also found. TMPTA allergy was not surprising as it had been reported previously. ${ }^{23}$

Having identified urethane acrylate as the causal agent, chemical analysis was carried out to ascertain whether TDI, acrylic acid, or some other contaminant from the chemical synthesis present in the commercial material might be the true allergen, rather than urethane acrylate. No detectable isocyanate was found; this, combined with the negative patch test response to TDI, excluded it as the cause. Unreacted acrylic acid could not be detected either, ruling it out as the cause. Accordingly, it was concluded that urethane acrylate was the source of the allergic contact dermatitis in the five workers with positive patch test reactions to urethane acrylate.

Two instances of positive epicutaneous tests to other acrylated chemicals were found in association with sensitivity to urethane acrylate. As cross reactivity between acrylates is uncommon, ${ }^{17}$ the chemical structures differ, and, in the instance of PETA, no contamination of urethane acrylate with it or an unreacted chemical was shown by chemical analysis, it is reasonable to conclude that as the individuals had been exposed to all three chemicals, the multiple causal reactions represent concurrent sensitisation rather than cross reactions. It is once again important to note, as has been noted in the past, that there was no cross reactivity shown between any of 
the acrylated chemicals and MMA, which has in the past been commonly used as a screening test for acrylate sensitivity.

Case 7 seems to have recurrent irritant contact dermatitis probably secondary to TMPTA, which is a moderately irritating material ${ }^{18}$ found in the inks. The irritancy of urethane acrylate determined by the Draize method in this report excludes it as the cause of irritation in case 7.19 EA resins, which also have low Draize scores, were excluded as likely causes on the same grounds.

Laboratory investigation of the sensitisation potential of urethane acrylate has confirmed its allergenicity. In table 3 the potential of MFAs used in these photo-cured materials as well as MMA and TDI are presented to allow a comparison of urethane acrylate with other chemicals with longer usage experience. Table 4 gives the results of past experiments with EA resins found in the same commercial products with their respective $\mathrm{IDSC}_{50}$ values. PETA has a very low IDSC $_{s 0}$ value relative to all of the other chemicals investigated; MMA has a relative high value. Thus the former chemical PETA seems to possess a high potential to induce cutaneous allergy, at least in the guinea pig, while the latter has a relatively low propensity to do so. These relative differences may overestimate the sensitisation potential of EA resins somewhat as the topical induction concentrations used in the EA resin experiments were higher than the concentration chosen for the chemicals in table 3 . Given this, these chemicals are probably either more or less potent allergens than MMA and PETA respectively, based on their IDSC $_{50}$ values.

The IDSC ${ }_{50}$ value for urethane acrylate has been extrapolated, and this value and that for EA 1,
EA 2, and EA (b) are thus not as accurate as the other values presented. Given this, urethane acrylate is likely to exhibit a sensitisation potential similar to TMPTA and less than the other MFAs, especially PETA. It may be a more potent allergen than MMA.

The usage experience presented in this report shows urethane acrylate to be a more potent allergen than TMPTA despite the experimental data from the animal investigation suggesting that the two chemicals possess similar allergenicity in the guinea pig.

How urethane acrylate relates to PETA in terms of the practical risk of causing skin allergy during use based on this group of workers is uncertain as exposure to PETA in this particular group is not known because the period of exposure to PETA in the ink formulations used was not ascertainable from the ink manufacturer. Previous usage experience with PETA $^{14}$ led to many ink formulation workers becoming allergic to it, much like the present instance with urethane acrylate in this group of workers. Whether PETA is a more or less potent allergen than urethane acrylate during use cannot be answered now as the conditions of exposure in this previous group of workers was not comparable with those reported herein. The previous workers were exposed to PETA as a raw material in an ink manufacturing process, whereas the present group handled urethane acrylate only as a component in finished ink products.

Urethane acrylate may be a less potent allergen than TDI based on these findings in the guinea-pig, despite the fact that isocyanate monomers are well known but infrequently documented skin allergens. ${ }^{120-22}$

Table 4 Percentage of animals sensitised, comparative sensitisation values, and various induction and challenge parameters for urethane acrylate resins

\begin{tabular}{lllllc}
\hline Chemical & $\begin{array}{l}\text { Intradermal } \\
\text { induction } \\
\text { concentration }\end{array}$ & $\begin{array}{l}\text { No of } \\
\text { animals }\end{array}$ & $\begin{array}{l}\text { No } \\
\text { sensitised }\end{array}$ & $\begin{array}{l}\text { \% Sensitised } \\
\text { by probit } \\
\text { calculations }\end{array}$ & $\begin{array}{l}\text { Intradermal sensitising } \\
\text { concentration for } 50 \% \text { of the } \\
\text { animals (IDSC }\end{array}$ \\
\hline in \%
\end{tabular}

*Topical induction concentration was $50 \%$.

†Topical induction concentration was $100 \%$.

‡Extrapolated value.

$\mathrm{NC}=$ No probit calculation performed . 
These experiments have shown the well recognised monomeric acrylate allergen ${ }^{1}$ to be a less potent allergen than the MFAs, urethane acrylate, EA resins, and TDI as illustrated by its IDSC $_{50}$ relative to those of the other chemicals as noted in tables 3 and 4 . The relatively low sensitisation potential of MMA is reflected in the low incidence of cutaneous sensitisation reported to it ${ }^{1}$ compared with the incidence of sensitisation to urethane acrylate in this group of workers.

Though urethane acrylate and TMPTA possessed equivalent allergenicity in the animal experiments, the lower apparent practical risk of sensitisation to TMPTA reflected in the relative incidence of cutaneous allergy to these two chemicals in this specific group of workers illustrates that animal studies, especially when one injects the chemical into the skin as in these experiments, may not correctly predict the practical risk of sensitisation in man or "predict the likelihood of sensitisation" in man-that is, risk.

The explanation for this disparity between the experimental and human experience with urethane acrylate and TMPTA may rest, in part, on the low irritancy of urethane acrylate, which has a Draize score of $0.75 / 8$ compared with TMPTA which has a score of $5 \cdot 2 / 8 .{ }^{17}$ This relative lack of irritancy of urethane acrylate has probably resulted in greater skin contact as the inks containing it would not irritate the skin, and workers would be inclined to leave the ink on the skin for longer periods, thus increasing the chance of sensitisation. This hypothesis does not fully explain the difference, though. EA resins, such as EA 1, EA 2, and EA (b) have IDSC $_{50}$ values much lower than urethane acrylate and lower irritancy based on their Draize scores. Despite this, they do not appear to sensitise appreciable numbers of those exposed to inks containing them. ${ }^{6}$ The explanation may rest in solubility differences that may affect cutaneous penetration, in turn altering the chance of penetration of the chemical into the skin and the chance of inducing allergy. The intradermal method of induction in the animal experiments circumvents this. In keeping with this, solubility differences definitely exist between EA resins and urethane acrylate wherein the former chemicals are not well solubilised in propylene glycol while the latter, as well as MFAs and MMA, are quite soluble.

Animal investigation can shed light on the relative ability of cutaneous contactants to induce allergy. Such information is useful when endeavouring to reduce the hazard of the use of chemicals known to sensitise. In such instances it may not be possible to use a material that is absolutely safe- that is, nonsensitising - but only relatively safe. Comparison of the sensitisation potential of potent allergens, taking intradermal induction concentration into consideration as illustrated in these experiments, may allow a more discriminating method of comparison or relative allergenicity than is provided by the standard grading system originally proposed by Magnusson and Kligman. ${ }^{14}$

The problem illustrated in this clinical situation with respect to such predictive laboratory tests is that the model considers relative sensitisation potential only within the confines of clearly defined, artificial conditions. Extrapolation to working conditions may have to take other factors into consideration, of which penetration through intact skin and likely exposure time in use are two. It is clear from the differences evident between the animal experiments and working circumstances with TMPTA, EA, and urethane acrylate that such predictions are complex.

Urethane acrylate resin is a cutaneous allergen that ranks comparably with PETA in its ability to cause allergic contact dermatitis when used in printing inks. The substitution of urethane acrylate for PETA offers no great health advantage. Both chemicals are relatively more hazardous than TMPTA, HDODA, or EA resin in this particular use.

\section{References}

${ }^{1}$ Nethercott J. Skin problems associated with multifunctional acrylic monomers in ultraviolet curing inks. $\mathrm{Br} J$ Dermatol 1978;95:541-52.

${ }^{2}$ Rybny C, DeFazio C, Shahidi I, et al. Ultraviolet radiation cured coatings. Journal of Paint Technology 1974;46:60-9.

${ }^{3}$ Rock W. Fissure sealants-results of a three year clinical trial using ultraviolet sensitive resin. Br Dent $J$ 1977:142:16-8.

4 Emmett E, Kominsky J. Health hazard evaluation. Cincinnati, Ohio: United States Department of Health, Education and Welfare, National Institute for Occupational Safety and Health, 1975. (Report No 75-106-247.)

5 Emmett E, Kominsky J. Allergic contact dermatitis from ultraviolet cured inks. JOM 1977;19:113-5.

- Emmett E. Contact dermatitis from polyfunctional acrylic monomers. Contact Dermatitis 1977;3:245-8.

7 Nethercott J. Allergic contact dermatitis due to epoxy acrylate. Br J Dermatol 1981;104:697-703.

seurey J, Monzeolle J-M, Weber M. Accidents cutanes des resines acryliques dans l'imprimerie. Annales de Dermatoloqie et de Syphiligraphie 1976;103:423-7.

- Bjorkner B, Dahlquist I, Fregert S. Allergic contact dermatitis from acrylates in yltraviolet curing inks. Contact Dermatitis 1980;6:405-9.

${ }^{10}$ Bjorkner B. Sensitization capacity of acrylated prepolymers in ultraviolet curing inks tested in the guinea pig. Acta Derm Venereol (Stock) 1981;61:7-10.

"Hannuksela M. Epicutaneous testing. Allergy 1979;34:5-10.

12 Fisher A. Contact dermatitis. Philadelphia: Lea and Febiger, 1975:183.

${ }^{13}$ Lever W, Schaumberg-Lever G. Histopathology of the skin. 5th ed. Philadelphia: JG Lippincott, 1975:100.

14 Magnusson B, Kligman A. Allergic contact dermatitis in the guinea-pig. Springfield: Charles C Thomas, 1970.

is Reed I, Muench H. A simple method of estimating fifty per cent endpoints. Am J Hyg 1938;27:493-7. 
${ }^{16}$ Draize J, Woodard G, Caivery H. Methoas tor study of irritation and toxicity of substances applied topically to the skin and mucous membranes. Journal of Pharmacology and Experimental Therapeutics 1944;82:377-90.

17 Jordan W Jr. Cross-sensitization patterns in acrylate allergies. Contant Dermatitis 1975;1:13-5.

${ }^{18}$ Anon. Celanese multifunctional acrylates and monomers in conventional coatings and adhesives. New York: Celanese Chemical Corporation. (No date given.)

${ }^{19}$ Steinberg M, Akers W, Weeks M, et al. A comparison of test technique based on rabbit and human skin responses to irritants with recommendations regarding the evaluation of mildly and moderately irritating compounds. In: Maibach $\mathrm{H}$ ed. Animal models in dermatology. Edinburgh: Churchill-Livingston, 1975;1-11.

${ }^{20}$ Zapp J. Hazards of isocyanates in polyurethane foam plastic production. Archives of Industrial Health 1957;15:324-9.

${ }^{21}$ Hjorth N. Dermatitis from hexamethylene diisocyanate. Contact Dermatitis 1975;1:59-61.

${ }^{22}$ Emmett E. Allergic contact dermatitis due to urethane foam. JOM 1977;19:113-5.

${ }^{23}$ Bjorkner B. Allergenicity of trimethylol propane triacrylate in ultraviolet curing inks in the guinea-pig. Acta Dermato Venereol (Stock) 1980;60:528-31. 